\title{
Una revisión de Pedro Rodrigo Sabalette sobre la poliomielitis (1948)
}

\section{A review of Pedro Rodrigo Sabalette about polio (1948) Uma revisão de Pedro Rodrigo Sabalette sobre poliomielite (1948)}

\author{
Francisco Herrera-Rodríguez \\ Facultad de Enfermería y Fisioterapia (Universidad de Cádiz)
}

Cómo citar este artículo en edición digital: Herrera-Rodríguez, F. (2015). Una revisión de Pedro Rodrigo Sabalette sobre la poliomielitis (1948). Cultura de los Cuidados (Edición digital) 19, 41. Disponible en: http://dx.doi.org/10.14198/cuid.2015.41.08> Correspondencia: Francisco Herrera-Rodríguez. Facultad de Enfermería y Fisioterapia. Avda. Ana de Viya, 52. 11009-Cádiz. Correo electronico: francisco.herrera@uca.es

Recibido: 3/11//2014; Aceptado: 11/01/2015

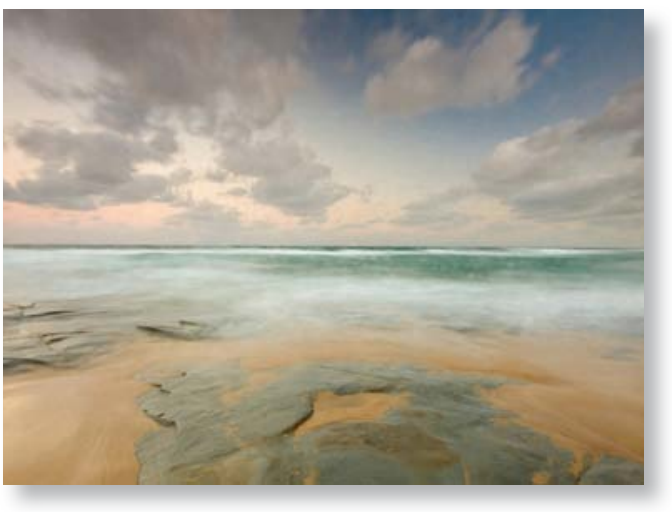

ABSTRACT

Although Pedro Rodrigo Sabalette (19041947) was an important personality in the Spanish Medicine in the first third of the 20th century, nowadays he is a forgotten figure. As he died in his youth, he was not able to develop the best of his clinical, teaching and researching aspects. He contributed to the Manual de Patología Médica, edited by Misael Bañuelos, in which he wrote the chapter on diseases of the central and peripheral nervous system; one of those items was about poliomyelitis. We have used in our study the sixth edition of the mentioned Manual, published in 1948 when Rodrigo Sabalete was already dead. Those pages on poliomyelitis are a source of great interest to know what the knowledge of that disease was in the late 1940's in aspects such as: etiologi- cal, pathogenic, clinical-anatomopathological, prophylactic and therapeutic.

Key Words: Poliomyelitis, Poliomyelitic's syndromes, Spain, 20th century, Postwar years, Pedro Rodrigo Sabalete.

\section{RESUMO}

Pedro Rodrigo Sabalette (1904-1947) é um proeminente, agora esquecido, o medicamento espanhol início do século XX figura. Ele morreu em sua juventude, quando ele ainda tinha que desenvolver o melhor de sua experiência clínica, ensino e pesquisa. Manual de Contribuição de Patologia Médica liderada por Misael Bañuelos, assumir o comando do capítulo sobre as doenças do sistema nervoso central e periférico, que incluía uma seção sobre a poliomielite. Nós utilizado em nosso estudo, a sexta edição do Manual, que viu a luz em 1948, quando Rodrigo Sabalette tinha morrido. As páginas dedicadas a pólio são uma fonte de grande interesse para conhecer o estado de conhecimento de que a doença no final dos anos quarenta, ambos aspectos etiológicos, patogénico, clínicas, patológicas, profilático e terapêutico.

Palavras-chave: Polio, síndromes poliomielite, Espanha, Siglo XX, do pós-guerra, Pedro Rodrigo Sabalette. 


\section{RESUMEN}

Pedro Rodrigo Sabalette (1904-1947) es una figura destacada, hoy día olvidada, de la medicina española del primer tercio del siglo XX. Falleció en plena juventud cuando aún tenía que desarrollar lo mejor de su experiencia clínica, docente e investigadora. Colaboró en el Manual de Patología Médica dirigido por Misael Bañuelos, encargándose del capítulo dedicado a las enfermedades del sistema nervioso central y periférico, en el cual incluyó un apartado dedicado a la poliomielitis. Hemos utilizado en nuestro estudio la sexta edición del citado Manual, que vio la luz pública en 1948 cuando ya había fallecido Rodrigo Sabalette. Las páginas dedicadas a la poliomielitis constituyen una fuente de gran interés para conocer el estado de los conocimientos de la citada enfermedad a finales de los años cuarenta, tanto en los aspectos etiológicos, patogénicos, clínicos, anatomopatológicos, profilácticos y terapéuticos.

Palabras Claves: Poliomielitis, Síndromes poliomielíticos, España, Siglo XX, Posguerra, Pedro Rodrigo Sabalette.

\section{JUSTIFICACIÓN Y OBJETIVO}

Dentro de la línea de trabajos que en los últimos años hemos realizado sobre la poliomielitis, presentamos este estudio dedicado a una figura médica escasamente recordada en la bibliografía, Pedro Rodrigo Sabalette (19041947), que falleció en plena juventud, cuando se esperaba mucho de su labor docente, clínica e investigadora. Aún así la labor realizada hasta su fallecimiento no fue poca, como tendremos ocasión de comprobar. Falleció en el mes de agosto de 1947, en Cádiz, en la trágica explosión de unas minas que acabó no solo con su vida sino con la de más de un centenar de personas (Marchena, 1997; Herrera, 1997).
Pedro Rodrigo Sabalette se desplazó desde Sevilla para pasar aquel verano con su familia en Cádiz, ciudad en la que residía su padre y mentor, Leonardo Rodrigo Lavín (1862-1950) (Herrera, 2007). La trágica explosión truncó su vida y por ende todo su potencial docente, clínico e investigador. A pesar de su trágico final, pensamos que es una figura médica que hay que valorar en el contexto de la medicina gaditana y española de la primera mitad del siglo XX, sobre todo si tenemos en cuenta su gran formación clínica en el extranjero en los años treinta, de la cual dejaremos constancia en estas páginas.

El objetivo de este trabajo, pues, es el siguiente: Exponer el estudio que sobre la poliomielitis publicó Pedro Rodrigo Sabalette en el "Manual de Patología Médica", dirigido por Misael Bañuelos, en 1948.

\section{SÍNTESIS BIOGRÁFICA}

Pedro Rodrigo Sabalette nació en Belascoin (Navarra), en junio de 1904, y falleció, como hemos indicado en el mes de agosto de 1947 (figura 1). Su padre, Leonardo Rodrigo Lavín (1867-1950), era catedrático de la Facultad de Medicina y durante muchos años desempeñó la inspección provincial de Sanidad de Cádiz. El joven Pedro Rodrigo encontró, sin duda, en la figura paterna la orientación necesaria para profundizar en la fisiología del sistema nervioso y en las enfermedades infectocontagiosas, debido a la doble dedicación profesional de su padre y el rigor con que éste realizó sus tareas docentes, investigadoras y epidemiológicas durante décadas en Cádiz. El camino, pues, lo tenía allanado en este sentido; pero todo esto no habría fructificado sin el esfuerzo personal de Rodrigo Sabalette que lo llevó, en plena juventud, a alcanzar la cátedra de Patología Médica en la Universidad de Sevilla. 


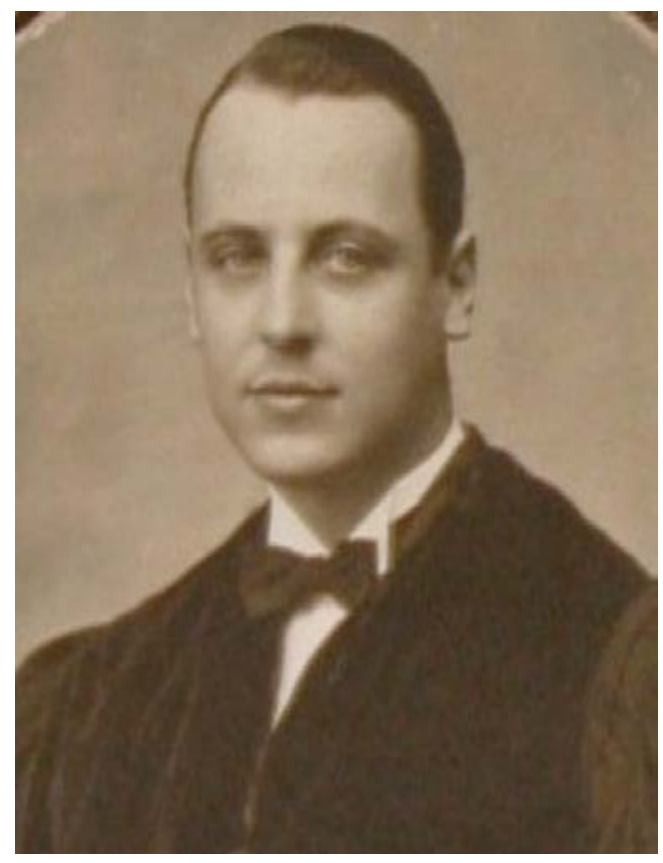

Figura 1: Fotografía de Pedro Rodrigo Sabalette (Fondo Antiguo de la Biblioteca de Ciencias de la Salud, Universidad de Cádiz)

Pedro Rodrigo Sabalette estudió la carrera de medicina en la Facultad de Cádiz, consiguiendo un brillante expediente académico, además de desempeñar la plaza de alumno interno (Herrera, 2001). El 12 de febrero de 1926 defendió su tesis doctoral en la Facultad de Medicina de la Universidad Central con el tema titulado "De la actividad tónica de los músculos estriados y su posible registro gráfico". Obtuvo la calificación de Sobresaliente por unanimidad, estando integrado el tribunal que lo calificó por los doctores Simonena, Forns, Calatayud, Menéndez Potenciano y Corral. La citada tesis fue publicada en Cádiz en 1926. Se debe apuntar que sobre este tema ya había investigado su padre y mentor, Leonardo Rodrigo Lavín, algunos años atrás (Herrera, 2007).

Ejerció como médico auxiliar del servicio de Profilaxis Públicas de las enfermedades venéreas de Cádiz y ganó las oposiciones del Cuerpo de Sanidad de la Armada (1924) y del Cuerpo de Inspectores de Sanidad de España (1927). En los años veinte y principio de los treinta realizó diversas estancias en el extranjero para ampliar su formación médica, por ejemplo: Departamento de Sanidad Pública del King's College (Universidad de Londres); Escuela de Oceanografía de la Dirección General de Pesca del Ministerio de Marina, donde realizó el curso de "Oceanografía Química del mar y Biología aplicada"; Facultad de Medicina de Estrasburgo, en los servicios de los profesores Brum y Merklen (1926-27 y 1927-28). En el Hospital de la Pitié (París), en 1928, realizó un curso de Cardiología, Electrocardiografía y Radiología del corazón con los profesores Gerandel y Bordet; en la Clínica Médica del Hospital de La Charité de Berlín, en 1929, estuvo de junio a septiembre, concretamente en el Laboratorio de Neurología de F.H. Lewy. Desde el mes de abril al de junio de 1930 se matriculó en un curso de Endocrinología, en Génova, con el profesor Pende, y de junio a diciembre del mismo año visitó la clínica del profesor Krehl en Heidelberg. En el verano de 1931 estuvo formándose en Estrasburgo en la clínica Neurológica del Prof. Barré, y de junio a octubre de 1933 visitó el Departamento de Radiología de la Universidad de Berlín. En 1932, a propuesta de la Facultad de Medicina de Cádiz, asistió al XIV Congreso Internacional de Fisiología. Asimismo fue pensionado por la citada Facultad en Alemania en los veranos de 1928, 1929 y 1931 (Herrera, 2001). Como se puede apreciar una formación en el extranjero intensa y extensa, en la que tuvo especial interés en cultivar, entre otros aspectos, la Neurología, circunstancia que en parte motiva este trabajo monográfico sobre sus aportaciones al estudio de la poliomielitis. 
Como docente fue ayudante de clases prácticas en las cátedras de Patología General, Dermatología y Sifilografía en la Facultad de Medicina de Cádiz. Y como profesor encargado de Patología General (1928-1930) y de Patología Médica (1931-1932). Ganó las cátedras de Patología General de Sevilla, Cádiz y Valladolid, y además las de Patología Médica de Sevilla y Valladolid. En noviembre de 1932 fue nombrado catedrático de Patología Médica de la Facultad de Medicina de Cádiz, plaza en la que cesó en febrero de 1935 para tomar posesión de la cátedra de esta disciplina en la Facultad de Sevilla.

En 1929 fue nombrado Académico de Número de la Real Academia de Medicina de Cádiz, ingresó con un discurso sobre "La acción de algunas sustancias vegetativotropas sobre el tono muscular". En 1933 organizó cursos de electrocardiografía y ejerció como médico del Dispensario Antituberculoso de Cádiz. Ofreció conferencias sobre "La enseñanza de la Patología y Clínica Médica en España y otros países" (1932) y la "Concepción actual y tratamiento de la Uremia” (1934), etc. (Herrera, 2001).

En 1941 publicó en Barcelona, en la editorial Científico-Médica, una monografía de 108 páginas titulada "El cáncer primitivo de pulmón”. Pero sobre todo queremos destacar, por el interés que tiene con respecto al objetivo que nos hemos planteado en este artículo, el extenso capítulo titulado "Enfermedades orgánicas del Sistema Nervioso Central y Periférico", que publicó póstumamente en 1948, en el "Manual de Patología Médica", dirigido por el catedrático de la Facultad de Medicina de Valladolid, Misael Bañuelos García (1887-1954) (Díaz- Rubio, 2000). Dentro de este capítulo escrito por Rodrigo Sabalette encontramos un apartado específico dedicado a los "Síndromes poliomielíticos" y dentro del mismo varias páginas sobre la "Parálisis espinal infantil epidémica o poliomielitis anterior aguda de la infancia", al que dedicaremos especial atención en este artículo.

Como hemos indicado anteriormente, Pedro Rodrigo Sabalette, falleció trágicamente en la explosión acaecida en Cádiz en agosto de 1947 y no pudo ver publicado su capítulo en la obra dirigida por Misael Bañuelos, motivo por el cual en el tomo II (sexta edición, 1948), se publica una nota redactada en octubre de 1947:

"El eminente internista y expertísimo neuropatólogo, Don Pedro Rodrigo Sabalette, nuestro ilustre colaborador, murió trágicamente, víctima de la horrible catástrofe que asoló la ciudad de Cádiz (...). El Editor y el Director de esta obra lamentan y sienten la muerte del insigne catedrático de la Universidad de Sevilla, como lo lamentan todos cuantos trataron a tan bondadoso y perfecto caballero, modelo de ciudadanos y hombres cultos de su tiempo.

En honor a su memoria, tan querida, y como tributo de homenaje a su recuerdo, se publica en esta edición su capítulo sobre "Enfermedades del Sistema Nervioso" tal cual como él nos lo entregara para la quinta edición, teniendo en cuenta por otra parte, que en tan breve tiempo transcurrido no han surgido novedades fundamentales.

Leves adiciones, surgidas en nuestra correspondencia con el querido amigo, muerto tan inesperadamente, son las únicas alteraciones. Octubre 1947".

Centraremos, pues, nuestros comentarios en este artículo en las páginas dedicadas a la poliomielitis que publicó en el citado libro; pero previamente presentamos un breve planteamiento de la situación de la poliomielitis en España en la década de los cuarenta. 


\section{LA POLIOMIELITIS EN ESPAÑA EN LOS AÑOS CUARENTA}

Con los datos estadísticos que aportamos en este apartado pretendemos sólamente dibujar un marco que sirva para entender la situación que se padeció en España con la poliomielitis en la década de los cuarenta, y así comprender la importancia de que fueran redactados capítulos específicos sobre la enfermedad en los manuales y tratados de Patología Médica, como el publicado de forma póstuma por Pedro Rodrigo Sabalette en 1948, en la sexta edición de la obra coordinada por Misael Bañuelos, aunque ya hizo lo propio también en la edición anterior.

Según los datos publicados por González Rodríguez, en 1953, el nivel epidémico de la poliomielitis aumentó considerablemente en Norteamérica a partir de 1944, ya que de un promedio de 7.000 a 8.000 casos anuales subió bruscamente a 19.000 en el referido año, y en los años siguientes siguió la línea ascendente: 25.000 casos en 1946, 27.000 en 1947, 42.000 en 1949 y 32.000 en 1950, "todas estas cifras dadas en números redondos”. En lo referido a Europa este autor apunta lo siguiente:

"En Europa el nivel epidémico aumenta aproximadamente en un 100 por 100 a partir de 1936; aumentando mucho más en 1947, a expensas de unos 5.500 casos declarados en Alemania, unos 3.500 en Austria, unos 1.100 en Francia, unos 3.000 en Italia y unos 8.000 en Inglaterra, países en contacto estrecho con Estados Unidos de América, preguntándose Stowman si no tendrá relación con la epidemia americana de 1946 este aumento en la incidencia sobrevenido en Europa un año más tarde. Nada extraño tiene esa conjetura, puesto que ese nivel elevado se mantiene en los años 1949 (el de mayor incidencia americana) y 1950, en cuyo año, además de los países citados se aprecia un aumento de casos en Suecia, Dinamarca y España”.
Un Real decreto de 10 de enero de 1919 legisló la declaración obligatoria de los casos de 'parálisis', "pero solamente al organizarse el Departamento de Estadísticas Sanitarias de la Dirección General de Sanidad, en junio de 1930, no comienzan a recogerse sistemáticamente los casos de enfermedades de declaración obligatoria"; aunque desde 1929 se estudian detalladamente brotes epidémicos de alguna importancia como el de Madrid (1929), Santander (1930), Palma de Mallorca (1932), Valencia (1942) y Madrid (1950) (González Rodríguez, 1953). Este mismo autor confecciona, basándose en los datos publicados en el Boletín del Departamento de Estadísticas Sanitarias de la Dirección General de Sanidad, una serie de tablas en las que se recoge numéricamente los casos y defunciones declarados en cada provincia desde 1931 hasta 1951, exceptuando los años de la guerra civil, aunque aclara el autor que "estos datos se refieren a casos con parálisis, por ser costumbre en España declarar solamente estas formas clínicas". Matiza también González Rodríguez que las cifras de morbilidad deben estimarse como inferiores a la realidad a causa de la "omisión" en la declaración de casos por parte de los médicos en ejercicio; las cifras de mortalidad "son más fidedignas, por corresponder con las certificaciones de defunción presentadas en el Registro civil".

Las tablas que aquí presentamos están elaboradas a partir de los datos aportados por González Rodríguez (1953) (tablas I, II y III), autor que hizo un esfuerzo muy notable por analizar estadísticamente el problema de la poliomielitis en España. Como se puede apreciar en la tabla I, de 1940 a 1950, se contabilizan un total de 6.220 casos de "parálisis" en España, sobresale el año 1942 con 741 y 1943 con 593, pero sobre todo 1950 en que la cifra aumenta a 1.600 (tabla I). 
Tabla I: Casos de “parálisis” en España (19401950)

$\begin{array}{cc}\text { AÑOS } & \text { No DE CASOS } \\ 1940 & 358 \\ 1941 & 247 \\ 1942 & 741 \\ 1943 & 593 \\ 1944 & 532 \\ 1945 & 499 \\ 1946 & 311 \\ 1947 & 482 \\ 1948 & 335 \\ 1949 & 522 \\ 1950 & 1.600 \\ \text { TOTAL } & 6.220\end{array}$

Fuente: Elaboración propia a partir de los datos de Pedro González Rodríguez (Madrid, 1953)

En cuanto a las defunciones destacan 1942 con 65, 1943 con 79, y 1950 con 91 (tabla II).

Tabla II: Defunciones por “parálisis” en España (1940-1950)

$\begin{array}{cc}\text { AÑOS } & \text { No DEFUNCIONES } \\ 1940 & 28 \\ 1941 & 24 \\ 1942 & 65 \\ 1943 & 79 \\ 1944 & 53 \\ 1945 & 29 \\ 1946 & 31 \\ 1947 & 50 \\ 1948 & 18 \\ 1949 & 43 \\ 1950 & 91 \\ \text { TOTAL } & 511\end{array}$

Fuente: Elaboración propia a partir de los datos de Pedro González Rodríguez (Madrid, 1953)
En la tabla III hemos sintetizado las tasas de morbilidad por 100.000 habitantes en las provincias andaluzas desde 1940 a 1950 . Centramos los comentarios en Andalucía sobre todo por entender mejor la incidencia de la poliomielitis en esta región, debido a que Pedro Rodrigo Sabalette fue catedrático de Patología Médica primero en Cádiz y posteriormente en Sevilla hasta la fecha de su muerte. Seguramente Sabalette tendría presente la morbilidad y la mortalidad ocasionadas por la poliomielitis en el conjunto de España, pero quizás prestaría más atención a los datos de las provincias más cercanas a Sevilla, lugar donde ejercía su cátedra en los años cuarenta. Llama la atención precisamente que las cifras más bajas las presenta la provincia de Sevilla, mientras que la de Cádiz presentó una incidencia de 6,27 y de 5,58 por 100.000 en los años 1944 y 1949. En este último año la provincia de Córdoba presentó una tasa de 7,56 y la de Málaga 8,44 en 1944. Pero sobre todo destaca la provincia de Huelva en 1942 con 15,20 y la provincia de Granada en 1943 con 16,63 (tabla III).

Tabla III: Morbilidad por 100.000 habitantes en las provincias de Andalucía (1940-1950)

\begin{tabular}{|l|c|c|c|c|c|c|c|c|c|c|c}
\hline PROVINCIAS & 1940 & 1941 & 1942 & 1943 & 1944 & 1945 & 1946 & 1947 & 1948 & 1949 & 1950 \\
\hline ALMERÍA & 0,91 & - & - & 4,54 & 1,09 & 1,58 & 1,08 & 2,93 & - & - & 3,22 \\
\hline CADIZ & 1,20 & 1,19 & 4,06 & 1,71 & 6,27 & 3,39 & 2,09 & 2,80 & 1,56 & 5,58 & 3,92 \\
\hline CORDOBA & 0,14 & 1,30 & 5,54 & 1,28 & 5,55 & 4,44 & 0,83 & 2,93 & 2,92 & 7,56 & 3,00 \\
\hline GRANADA & 0,2 & 0,26 & 0,92 & 16,63 & 4,26 & 3,44 & 0,65 & 3,72 & 1,22 & 3,05 & 1,56 \\
\hline HUELVA & 0,29 & 0,27 & 15,20 & 6,48 & 6,22 & 2,13 & 0,80 & 2,27 & 1,06 & 0,79 & 2,91 \\
\hline IAEEN & 0,91 & 0,26 & 0,13 & - & 0,63 & 3,91 & 1,07 & 1,89 & 0,37 & 1,24 & 1,68 \\
\hline MÁLAGA & 0,89 & 1,63 & 2,03 & 4,77 & 8,44 & 2,82 & 2,65 & 4,01 & 3,59 & 2,04 & 2,04 \\
\hline SEVILLA & 0,55 & 0,20 & 0,40 & 1,55 & 1,45 & 0,54 & 0,75 & 1,49 & 0,89 & 1,06 & 2,18 \\
\hline
\end{tabular}

Fuente: Elaboración propia a partir de los datos de Pedro González Rodríguez (Madrid, 1953)

Sirvan estos datos, pues, de marco general para entender la situación por la que atravesaba España y concretamente Andalucía con respecto a la poliomielitis en la década de los cuarenta. 


\section{REVISIÓN DE PEDRO RODRIGO SABA-} LETTE SOBRE LA POLIOMIELITIS (1948)

El capítulo redactado por Pedro Rodrigo Sabalette para esta obra colectiva, dirigida por Misael Bañuelos, abarca 264 páginas y lleva por título "Enfermedades orgánicas del Sistema Nervioso Central y Periférico". En este capítulo Sabalette dedica un apartado a los "Síndromes poliomielíticos", en el que incluye a la "parálisis espinal infantil epidémica o poliomielitis anterior aguda de la infancia", la "poliomielitis anterior subaguda y crónica", la "parálisis ascendente aguda o sindrome de Landry" y el "herpes zóster". Dedicaremos especial atención a la "parálisis espinal infantil epidémica o poliomielitis anterior aguda de la infancia" y al resto de los epígrafes señalados un breve comentario.

Pensamos que tiene interés estudiar el estado de la cuestión sobre la poliomielitis planteado por Pedro Rodrigo Sabalette, a finales de los años cuarenta, ya que este manual de Patología Médica de Misael Bañuelos, en el que se incluye su trabajo, fue muy utilizado tanto por especialistas, médicos generales y estudiantes de medicina, y tuvo influencia no solo en España sino también en países de Sudamérica.

La primera cuestión que apunta Sabalette es que la poliomielitis anterior aguda de la infancia debería denominarse "Enfermedad de Heine-Medin"; enfermedad que "ni afecta de modo exclusivo a los niños, ni reviste en todos los casos carácter epidémico". Sobre este punto se debe aclarar que Jakov Von Heine, en Alemania, en 1840, observó un número considerable de casos tardíos, aunque en 1836 el anatomista Charles Bell realizó un informe de la que se podría considerar una epidemia causada por la enfermedad, concretamente en la isla de Santa Elena se presentaron varios casos de 'parálisis' en niños. En 1868 se notificaron 14 casos en Noruega; Cordier, entre 1880 y 1890, describió brotes en Francia, y a finales de la década de los ochenta lo hizo Karl-Oskar Medin en Suecia (Axelsson, 2009; Paul, 1956). Medin, en 1887, incorporó a la mielitis otras afecciones bulbares, encefalíticas y atáxicas (Ferrán Martínez Navarro, 2013). Cabe recordar también que en 1855, Duchenne de Boulogne, publicó en París, una memoria titulada "De la paralysie atrophique graisseuse de l'enfance" (Laval, 2007). Una excelente síntesis sobre la emergencia epidémica de la poliomielitis a finales del siglo XIX y principios del siglo XX ha sido realizada por Ballester y Porras Gallo (2012). Leamos:

“...la emergencia epidémica de la polio arrancó con la epidemia de 1881 del noroeste de Suecia, que dio pasos a sucesivos brotes epidémicos de magnitud creciente, limitados inicialmente a Escandinavia, aunque ocasionalmente afectaron también a Italia (1883), Alemania (1884) y Francia (1885). Durante la década final del siglo XIX la intensidad epidémica de la polio se multiplicó y alcanzó mayor extensión europea. Se produjeron las primeras epidemias en Inglaterra (1896), España (1896) y Austria (1897), pero también en los EEUU y Canadá. La expansión europea y norteamericana de las epidemias de polio se acentuó en la primera década del siglo $X X$, registrándose la transición desde pequeños brotes epidémicos con menos de veinticinco casos a otros más graves con más de cien casos".

Sabalette presenta el estudio de la enfermedad de una manera clásica y estructura la exposición en varios apartados: etiología y epidemiología, anatomía patológica y patogenia, sintomatología y curso clínico, formas clínicas, diagnóstico y pronóstico, el tratamiento y la profilaxis. 


\subsection{Etiología y epidemiología}

En el planteamiento sobre la causa de la enfermedad presenta Sabalette el carácter infeccioso de la misma, apoyándose en los trabajos clásicos de Landsteiner, Flexner, Noguchi y Levaditi; autores, señala, que provocaron un cuadro experimental de poliomielitis, inoculando a monos el filtrado de macerados de médula procedentes de niños muertos de esta enfermedad. Y sobre todo Sabalette señala a Flexner y Noguchi, en 1913, como los que describieron "unos diminutos corpúsculos, cuerpos globoides (globoides bodies), desprovistos de movimientos propios, de 0,15 a 0,30 micras de longitud, agrupados habitualmente en parejas, cortas cadenetas o pequeños conglomerados y tingibles por el GRAM y la coloración de GIEMSA, a los que se considera hoy como los gérmenes productores de la enfermedad". Recuérdese que algunos estudiosos señalan a Landsteiner y Popper como los decubridores del virus en 1908 (Paul, 1956). Otros autores como Glanzmann señalan a Landsteiner y Popper como los autores que en 1909 consiguieron transmitir la enfermedad al mono inyectando directamente en el cerebro emulsión de médula de niños fallecidos como consecuencia de la poliomielitis. El propio Glanzmann, en 1913, hizo un experimento semejante en Berna, y comprobó que después de inyectar al mono se le paralizó a éste la mitad de la cara, el brazo izquierdo y ambas piernas, "muriendo a consecuencia de la poliomielitis inoculada" (Glanzmann, 1946). En cuanto a los descubrimientos de Levaditi, Hydayo, Noguchi y Simon Flexner sobre el virus causal de la enfermedad deben consultarse los trabajos de Báguena Cervellera (2004 y 2009). González Iglesias ha señalado que la demostración del virus en las vías digestivas altas y bajas fue hecha ya en 1912 por Kling y Pettersson, pero entonces no se le dio la debi- da importancia, a pesar de haber demostrado Kling la presencia del virus en las heces fecales de enfermos de poliomielitis. En 1939, el propio Kling, demostró que el virus persistía en las heces de los enfermos hasta tres meses después del comienzo de la enfermedad. A partir de esta fecha y de los trabajos de Sabin y Ward se suceden las observaciones y experiencias quedando demostrado el aislamiento del virus en la cavidad nasofaríngea y en el intestino delgado y grueso. González Rodríguez lo explica así:

"...en la cavidad nasofaríngea y en el intestino delgado y grueso; que en la cavidad nasofaríngea permanece poco tiempo, los cinco días que preceden a la enfermedad y los cinco primeros días de ésta, y que en las heces fecales y productos del lavado intestinal puede encontrarse el virus tres semanas antes del comienzo de la enfermedad, persistiendo mucho tiempo después, hasta unas diez o doce semanas. Pero el hallazgo de mayor valor epidemiológico en estos últimos años ha sido la demostración del virus en la faringe $y$ en las heces fecales de personas sanas o carentes de sintomatología clínica que han estado en contacto con enfermos de parálisis infantil, $y$ aun en personas en que no se ha confirmado ninguna relación con esta clase de enfermos".

Sobre el modo de transmisión más generalmente admitido a finales de la década de los cuarenta, Pedro Rodrigo Sabalette señala que es de persona a persona, "aunque no esté desechada en absoluto la posibilidad del contagio indirecto, por medio de objetos, de ciertas substancias alimenticias (leche, agua) y hasta de ciertos animales (moscas). En cuanto a hipótesis epidemiológica, a partir de experimentos y de la experiencia clínica de las últimas epidemias, el tipo de infección de esta enfermedad parece adscribirse al de "infección 
por gotas", teniendo los portadores "sanos" un papel "de mucha mayor importancia que los mismos enfermos". Recuérdese que la hipótesis de la transmisión hídrica se formuló por el hallazgo de la presencia del virus en el intestino de los sujetos infectados, se demostró que la colonización nasofaríngea era una fase transitoria mientras que la intestinal era la definitiva. Cabe recordar también que el papel de la mosca de los establos (Stomoxys calcitrans) en la transmisión pasiva de la enfermedad fue apuntado por Rosenau en 1913 (Ferrán Martínez Navarro, 2013). Sabalette insiste en esta cuestión y ofrece una panorámica de las incertidumbres que a mediados y finales de los años cuarenta existían entre los investigadores. Leamos:

"Efectivamente, las recientes investigaciones, realizadas sobre todo por autores americanos, han podido demostrar que el exudado rinofaríngeo de un gran número de personas sanas que habitan en un foco epidémico contiene material infectante, vista la posibilidad de su inoculación en los animales electivos: el mono y, en mucho menor grado, el conejo. Últimamente Ayckhoff y Kramer han comprobado en la sangre de convalecientes de poliomielitis y en la de ciertos portadores la existencia de una antitoxina que se muestra activa frente a la simiopoliomielitis experimental. Las comprobaciones experimentales resultan muy laboriosas y costosas porque los animales en los que la enfermedad es experimentalmente factible son muy escasos, hecho tanto más desconcertante si se considera que simultáneamente con las epidemias de poliomielitis se presentan, casi siempre, distintas epizootias, entre ellas la enfermedad de Borna (nombre de la localidad sajona en que primero se observó y estudió), que afecta con predilección a los caballos y aves, y que, en ciertos aspectos, se parecen extraordinariamente a la enfermedad de Heine-Medin (carácter epidémico contemporáneo, cuadro clínico de parálisis, filtrabilidad del germen productor)".

En 1948, el mismo año de la edición del capítulo de Sabalette, Florencio Pérez Gallardo (figura muy destacada de la salud pública española en la posguerra, que en esa fecha publicó un extenso artículo titulado "Epidemiología y profilaxis de la poliomielitis"), señaló también como principal limitación en la investigación etiológica de la poliomielitis la dependencia de los monos como animales de investigación (Ferran Martínez Navarro, 2013; Nájera, 2006).

Sabalette señala que la poliomielitis afecta principalmente a niños pequeños, pero no de modo exclusivo; documenta este aspecto con los estudios de Tapia sobre la epidemia de Madrid de 1929, autor que apunta 112 observaciones, de las cuales 104 fueron niños de uno a tres años de edad. González Rodríguez señala, en 1953, la tendencia creciente en el número de invasiones " $y$ su tendencia rebasadora de los límites de edad que habitualmente se tenían como clásicos, pues ya en muchos países no puede hablarse de enfermedad de la infancia, por afectarse casi en igual proporción niños y jóvenes adultos, notándose además que a medida que la enfermedad se desplaza a grupos de edades mayores aumenta la letalidad y aumenta el número de formas paralíticas graves, parálisis extensas de los miembros y formas bulbares $y$ cerebrales".

Otra cuestión. La enfermedad es más frecuente en las poblaciones rurales que en las urbanas; sobre este particular Rodrigo Sabalette argumenta que probablemente se deba al contacto más íntimo de los habitantes de las aldeas, aunque siembra la duda al sacar a colación la epidemia de Nueva York de 1933 que "ha respetado, casi por completo, la población 
rural". En cuanto a la estacionalidad de las epidemias constata que suelen presentarse al final del verano o a principio del otoño, coincidiendo con grandes lluvias. Goebels decía que "cuando el termómetro marca cero desaparece la polio"; sin embargo, no siempre se cumple este aforismo, no siendo raros los casos de parálisis en invierno y primavera (Cruz Hernández, 1972).

Rodrigo Sabalette señala también que la poliomielitis en España "no parece revestir" tanta importancia como en el centro de Europa o en América del Norte, pero no presenta datos estadísticos de morbilidad y mortalidad para corroborar su afirmación, con toda seguridad por el poco espacio que podía dedicar a la enfermedad en el contexto del capítulo de las enfermedades orgánicas del sistema nervioso en el referido libro. Pero como hemos podido comprobar anteriormente hay cifras de morbilidad muy llamativas, como las que padeció Huelva en 1942, Granada en 1943 y Málaga en 1944 (tabla III). O los casos contabilizados en España en los años citados (tabla I).

En cuanto a la aparición de los brotes epidémicos, Sabalette señala a la exaltación de la virulencia de los gérmenes, el decrecimiento de la inmunidad adquirida, "jugando también un papel las condiciones locales del exudado rinofaríngeo y las infecciones asociadas que tan manifiestas son en muchos casos mortales, en los que la autopsia demuestra una generalización de focos en todos los parénquimas".

\subsection{Anatomía patológica y patogenia}

Pedro Rodrigo Sabalette dedica un pequeño apartado a estos aspectos de la enfermedad. Señala como localización típica de las lesiones las células ganglionares del asta anterior de la médula lumbosacra, "aunque se admite generalmente una especial afinidad de la toxina poliomielítica con estas células y sus equivalentes mesocefálicas (en las localizaciones altas, atípicas de la enfermedad) no se puede excluir la importancia del factor hematógeno para explicar estas lesiones". Y ofrece una explicación detallada, acompañada de una ilustración de la irrigación arterial de la médula (figura 2):

"La arteria espinal anterior da ramos alternativos para ambas astas anteriores que resultan, de este modo, irrigadas casi exclusivamente por estos ramos; y la inyección de una suspensión de polvos de licopodio en la aorta de una animal produce una acumulación electiva del producto en los cuernos anteriores. Ahora bien, el camino recorrido por la infección a partir de la puerta de entrada está representado con toda verosimilitud por la vía hemática”.

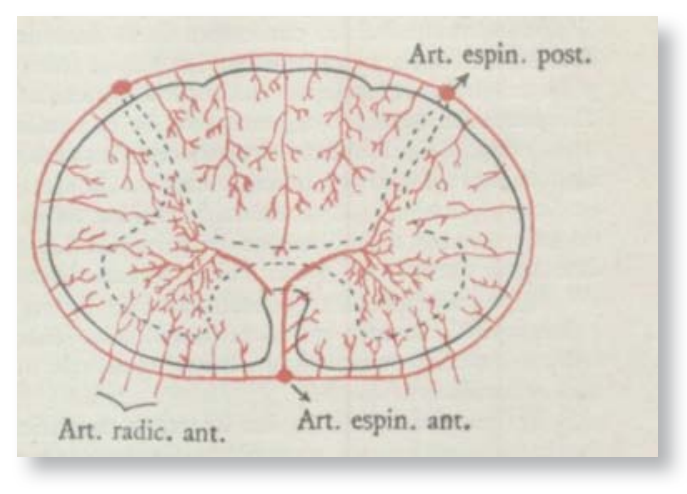

Figura 2: "Esquema de la irrigación arterial de la médula que explica la seudosistematización lesional de la poliomielitis" (Fuente: Rodrigo Sabalette, 1948)

En cuanto a la lesión principal señala que se produce a nivel de estas células motoras y con el microcopio pueden observarse "fenómenos de tigrolisis y neuronofagia muy intensos". Y añade:

"Hay también una discreta participación de la pía y un edema intersticial con extravasado de los linfáticos. La substancia gris aparece muy pálida y los límites con la substancia 
blanca, muy difuminados. En esta última hay, a veces, una verdadera inflamación intersticial, verdadera leucomielitis, sin que se presenten, sin embargo, degeneraciones secundarias".

No olvida señalar que en los casos graves, con infecciones asociadas, la anatomía patológica de esta enfermedad se complica mucho, observándose focos diseminados, de especial predilección pulmonar, de tipo bronconeumónico, y a veces "verdaderas pulmonías lobares".

En cuanto a la cicatriz anatómica escribe lo siguiente:

“...queda una intensa proliferación neuróglica en el asta anterior y una degeneración secundaria en las raíces motoras que se traducirá, clínicamente, en la atrofia de carácter degenerativo de los músculos correspondientes".

Glanzmann (1946) señala que las investigaciones anatomopatológicas demuestran que la parálisis infantil es una enfermedad de todo el organismo, "una toxicosis hemática, una sepsis", de manera que el miocardio, los riñones y el hígado aparecen como "cocidos", el bazo muy inflamado y agrandado, y todos los órganos están sumamente "hiperemiados". En cuanto a las mucosas de la nariz y de la faringe, así como en las vías respiratorias se observan señales de una inflamación catarral, "pudiendo comprobarse simultáneamente un catarro de la mucosa del intestino delgado $y$ del colón". Glanzmann, apoyándose en los trabajos de Walthard, apunta también que se observan hemorragias en la pleura, peritoneo y mucosas; sin embargo, "no ha sido posible hallar hasta la fecha al virus en la sangre (...), se encuentra muy rara vez en el líquido cefalorraquídeo o no se le halla, (...), probablemente el virus pasa por la sangre extraordinariamente de prisa, penetrando rápidamente en el sistema nervioso". El virus pasa de los vasos sanguíneos a las meninges del encéfalo y de la médula, y desde allí pueda atacar al cerebro y la médula, de manera que el virus daña principalmente a las grandes células ganglionares o neuronas de las que parten los impulsos del movimiento, especialmente de los brazos y de las piernas, ya que estas células poseen una gran irrigación sanguínea.

\subsection{Sintomatología, formas clínicas, diag- nóstico y pronóstico}

Rodrigo Sabalette explica la evolución clínica de los casos típicos de la enfermedad en tres períodos: "Un primer período de invasión, de estado infeccioso indeterminado; un segundo de aparición de parálisis y un tercero de regresión de las mismas".

La duración del primer periodo es variable, pero generalmente es de uno a cuatro días. Es un periodo febril con sintomatología "polimorfa y anespecífica". Aparecen síntomas como estreñimiento o diarrea y vómitos, o bien tos, afonía, estornudos y lagrimeos. Además de intranquilidad, cefalea y dolores erráticos y generalizados, "a veces verdadera raquialgia". En otras ocasiones aparece un periodo inicial de tipo meningítico, con rigidez de nuca y signo de Kernig, y "en ocasiones, insomnio pronunciado o somnolencia, o una tendencia a convulsiones epileptoides". En esta primera fase el diagnóstico es complicado porque se puede confundir con un estado infeccioso como, por ejemplo, el causado por la gripe. El diagnóstico es más fácil "con motivo de una epidemia y aun así es solamente un diagnóstico de presunción".

El segundo período está marcado por las parálisis, “...hacen su aparición inmediatamente de esta fase infecciosa; pero, a veces, lo hacen tan tempranamente que parecen primitivas". En ocasiones aparecen dolores localizados en los músculos que se paralizarán, pero esto no es una constante. Sobre la parálisis apunta: 
"La parálisis se extiende más o menos, con arreglo a la variabilidad individual de cada caso, pero lo típico suele ser el afectar a músculos de los miembros, en las formas habituales monopléjicas, parapléjicas o dipléjicas. La parálisis tiene, desde el primer momento, los caracteres de la flaccidez y los territorios afectos de parálisis suelen estar hipotérmicos. La exploración demuestra la hipotonía acentuada y la ausencia de reflejos tendinosos y periósticos. La exploración eléctrica nos da cuenta del carácter degenerativo de la parálisis (...). La punción lumbar practicada en esta fase suele demostrar la existencia de una discreta hipertensión del líquido cefalorraquídeo, acompañada generalmente de ligera hiperalbuminosis y pleocitosis (...). En el período febril suele comprobarse una ligera leucocitosis con neutrofilia y en las fases posteriores una reducida leucopenia".

Los síntomas paralíticos, en plazo variable, comienzan a disminuir "y quedan localizados en grupos musculares determinados". Normalmente quedan paralizados con más frecuencia los del grupo anteroexterno de la pierna, generando un pie equino o equinovaro, y en el miembro superior los músculos del antebrazo. Sabalette señala también que la parálisis residual de todo un miembro o de los músculos del tronco (periescapulares o abdominales), "no son, en manera alguna, excepcionales". Y matiza de esta manera:

"Los fenómenos generales desaparecen por completo y se entra entonces en la fase residual. Los músculos paralizados se atrofian (...) y se van constituyendo las deformidades e incapacidades definitivas. La enfermedad, en realidad, ha pasado y nos encontramos entonces frente a las secuelas de la misma”.

Lo descrito hasta aquí por Rodrigo Sabalette se refiere a "casos típicos" de la enfermedad; pero también señala las formas aborti- vas, en que sólo existe el primer período y las parálisis no llegan a aparecer, "casos que sólo pueden ser diagnosticados con motivo de ser observados en una epidemia”. Existen también "formas de sintomatología meníngea acentuada y otras en las que los fenómenos paralíticos van ascendiendo progresivamente hasta el punto de simular un síndrome de Landry". En cuanto a las localizaciones estudia las formas mielíticas, con trastornos esfinterianos pronunciados, $\mathrm{y}$ formas en las que se trata de una verdadera leucomielitis cuya manifestación clínica es un síndrome de parálisis espástica, con fenómenos piramidales y signo de Babinski. Si el proceso asienta fuera de la médula da origen a formas polioencefalíticas, con sintomatología de parálisis bulbar o de oftalmoplejía, o bien a formas encefalíticas con síntomas y lesiones cerebrales. Más raramente, se produce un síndrome cerebeloso o un síndrome polineurítico, "con parálisis de tipo periférico, dolores y parestesias".

En lo que se refiere al pronóstico, Sabalette apunta que la mortalidad de esta enfermedad es baja, "oscilando las cifras dadas en las distintas epidemias entre un 2 y un 8 por 100". La muerte en los casos desfavorables suele producirse por parálisis bulbar en las localizaciones altas, o por parálisis de los intercostales y del diafragma en las localizaciones espinales, aunque en ocasiones "un proceso intercurrente", como una bronconeumonía, puede acabar con la vida del paciente. En cuanto al porvenir de los pacientes pide prudencia: “...ha de ser muy reservado para cada caso, (...), al lado de casos con parálisis iniciales muy extendidas que llegan a regresar por completo, otros sin regresión, que dejan una invalidez permanente, a pesar de haber sido poco extendidos los fenómenos paréticos en un principio". 


\subsection{Profilaxis y tratamiento}

En este apartado reina el pesimismo en el texto de Rodrigo Sabalette. En lo que se refiere a la profilaxis señala como medida primordial el aislamiento del enfermo y de las personas cercanas, "teniendo en cuenta la importancia de los portadores sanos". Sin olvidar el cierre de escuelas y otros centros durante los brotes epidémicos. Este pesimismo estaba presente en la mayor parte de los autores de la época, aunque apuntaban medidas como el aislamiento de los enfermos, la higiene de los alimentos o la lucha contra las moscas (Ferrán Martínez Navarro, 2013). La estrecha relación entre la larga persistencia del virus poliomielítico en las heces y aguas de alcantarilla, y la transmisión de la parálisis infantil por intermedio de las moscas, es una cuestión señalada en la bibliografía a partir de los trabajos de Rosenau (González Rodríguez, 1953). Autores como John R. Paul, en los años cincuenta, señalaban a los portadores sanos, numerosos e incontrolados, porque su infección asintomática pasaba desapercibida, "no sólo al clínico sino también al funcionario de salud pública”. De manera que estas personas podían constituir un inmenso reservorio del virus " $y$ quizás son ellos los que mantienen el virus en una colectividad durante los intervalos interepidémicos". Recordemos que Pedro Rodrigo Sabalette insiste en su trabajo particularmente en este punto.

En cuanto al tratamiento Sabalette también se muestra pesimista, no existe "un arma realmente eficaz". Apunta el empleo precoz del suero de convaleciente y el suero antipoliomielítico de Pettit, "pero las conclusiones formuladas por algunos autores a este respecto -entre nosotros, por Tapia- son desconsoladoras”. A pesar de ello debe utilizarse en todos los casos por vía intravenosa y subcutánea. También hace referencia al tratamiento de Bordier con la diatermia de los músculos paralizados con la radioterapia profunda de las zonas medulares correspondientes, "es sólo aplicable en establecimientos hospitalarios y, por lo demás, existe un escepticismo creciente sobre los resultados que con él pueden obtenerse". Recomienda el reposo en cama y la utilización de urotropina por vía intravenosa. Y la punción lumbar, en las formas meníngeas, ya que alivian las cefaleas. En cuanto a las "parálisis definitivas, amiotrofias y posiciones viciosas" recomienda, sin desarrollar el tema, los "procedimientos ortopédicos apropiados". Y no hace mención a las técnicas de rehabilitación de la enfermera australiana Elizabeth Kenny (1880-1952), cuyo método tuvo detractores en 1944 (Barraquer y Sales, 1956; Herrera, 2011).

Como apuntamos anteriormente dentro de los "síndromes poliomielíticos", Sabalette además de la "poliomielitis anterior aguda de la infancia o parálisis espinal infantil epidémi$c a$ ", que acabamos de exponer, señala también la "poliomielitis anterior subaguda y crónica", que relaciona etiológicamente con la sífilis e intoxicaciones, "aunque los traumatismo también se han incriminado en algunas observaciones". Asimismo considera dentro de los referidos síndromes la "parálisis ascendente aguda o síndrome de Landry", "que puede ser producido por distintos procesos anatomopatológicos". Y, por último, también el "herpes zóster", justifica su inclusión de la siguiente manera y señala el desconocimiento de la etiología de esta enfermedad: "Incluímos el estudio de este proceso en este capítulo de síndromes poliomielíticos, porque, según toda probabilidad, la erupción de herpes zóster está condicionada por una verdadera poliomielitis posterior de los ganglios espinales y de sus homólogos de algunos pares craneales". 


\section{EPÍLOGO}

Misael Bañuelos García (1887-1954) dirigió desde mediados de los años treinta un "Manual de Patología Médica", que tuvo según apunta Díaz-Rubio, impacto fuera de España, "siendo libro de texto en muchas Facultades de España y de países de habla castellana". En esta obra dirigida por el médico burgalés, que fue primero catedrático de Patología Médica en la Facultad de Santiago de Compostela y posteriormente en Valladolid, colaboraron profesores como Juan Andreu Urra, Manuel Beltrán Báguena, José Casas Sánchez, Lorenzo Gironés, Agustín Pedro Pons, Fermín Querol, José María Villación y Pedro Rodrigo Sabalette. Este último autor, como hemos podido comprobar, se encargó y redactó por su formación clínica, llevada a cabo en primer lugar en Cádiz y posteriormente en diversas clínicas europeas, el capítulo titulado "Enfermedades orgánicas del sistema nervioso central y periférico". Capítulo en el que demuestra su conocimiento de la materia apuntada, a pesar de verse obligado por las características de la obra a ofrecer la información de forma muy compendiada.

Pedro Rodrigo Sabalette es una figura de la medicina española de la primera mitad del siglo XX, que aún no ha recibido un reconocimiento suficiente a su obra docente, clínica e investigadora, por este motivo tratamos de contribuir al conocimiento de su figura divulgando el documentado estudio que en el libro de Bañuelos realizó sobre la poliomielitis, enfermedad que en la década de los cuarenta y en las siguientes causó mucho daño en el mundo y también en España; tanto que se ha representado en el cine y en la literatura; véase, por ejemplo, la novela "Némesis" del escritor estadounidense Philip Roth, centrada en la epidemia de poliomielitis padecida en Newark en 1944 (Herrera, 2011). Pensamos que las páginas que Rodrigo Sabalette dedica a la en- fermedad en el referido Manual, dirigido por Misael Bañuelos, es una notable síntesis sobre el conocimiento de la enfermedad (etiología, patogenia, anatomía patológica, clínica, profilaxis y terapéutica), páginas que seguramente fueron muy estudiadas en los años cuarenta, tanto en España como en Sudamérica, por médicos y estudiantes de medicina.

\section{FUENTES:}

Para la realización de este trabajo se han utilizado las siguientes fuentes documentales:

- Expediente de profesor de Pedro Rodrigo Sabalette: Legajo 1994-B, expediente 11 (Archivo Histórico de la Universidad de Sevilla).

- Fotografía de Pedro Rodrigo Sabalette (Fondo Antiguo de la Biblioteca de Ciencias de la Salud de la Universidad de Cádiz).

- Diario de Cádiz: 16 de abril de 1929; 27 de febrero de 1932; 5 de febrero de 1933; 20 de abril de 1934.

- Rodríguez Sabalette, Pedro (1948): Enfermedades orgánicas del Sistema Nervioso Central y Periférico. En Bañuelos, M. (dir.): Manual de Patología Médica. Editorial Científico-Médica. Sexta edición. Barcelona, tomo II, 7-264.

\section{BIBLIOGRAFÍA}

- Axelsson, P. (2009). 'Do note at those apples; they've been on the ground!': Polio epidemics and preventive measures, Sweden 1880s-1940s. Asclepio. Revista de Historia de la Medicina y de la Ciencia, 1, 23-38.

- Báguena Cervellera, Ma .J. (2004). Saberes y prácticas en torno a la polio en la medicina valenciana (1900-1950). En Martínez Pérez, J. et al (coords.), La medicina ante el nuevo milenio: una perspectiva histórica. Cuenca: Editorial de la Universidad de Castilla-La Mancha, 949-962.

- Báguena Cervellera, Ma.J. (2009). Estudios epidemiológicos y virológicos sobre la poliomielitis en Valencia (1959-1969). Asclepio. Revista de Historia de la Medicina y de la Ciencia, 1, 39-54. 
- Ballester, R. y Porras, Ma.I. (2012). La lucha europea contra la presencia epidémica de la poliomielitis: una reflexión histórica. Dynamis, 2, 273-285.

- Barraquer Ferré, L. y Sales Vázquez, R. (1956). Poliomielitis. En Valero-Ribas, J. (Dir.). Enciclopedia Salvat de Ciencias Médicas. Barcelona: Salvat editores, SA, tomo IV, 535-543.

- Cruz Hernández, M. (1972). Pediatría y Puericultura. Barcelona: Editorial Romargraf., tomo 2º, 1553-1576.

- Díaz-Rubio, M. (2000). 100 médicos españoles del siglo XX. Madrid: Industrial Farmacéutica Cantabria, SA, 2021.

- Farreras Valentí, P. y Rozman, C. (1978). Medicina Interna. Barcelona: Editorial Marín, SA., t. II, 815 y ss.

- Ferrán Martínez Navarro, J. (2013). Los estudios epidemiológicos sobre la poliomielitis en España antes de la vacunación. Revista Española de Salud Pública, 5, 429441.

- Glanzmann, E. (1946). La parálisis infantil epidémica (poliomielitis). Barcelona: Ediciones BYP.

- González Rodríguez, P. (1953). Aspectos epidemiológico y social de la poliomielitis. La parálisis infantil en España (folleto para médicos). Madrid: Dirección General de Sanidad.

- Herrera Rodríguez, F. (1997). Exposición “50 años de la explosión de Cádiz" (1947-1997). Llull. Revista de la Sociedad Española de Historia de las Ciencias y de las Técnicas, 38, 333-335.

- Herrera Rodríguez, F. (2001). El Colegio Oficial de Médicos de la Provincia de Cádiz en la posguerra. En Cabrera, J.R. y Herrera, F. (dirs.), El Excmo. Colegio Oficial de Médicos de la provincia de Cádiz en el siglo XX. Conmemoración de su Centenario (1901-2001)”. Cádiz: Excmo. Colegio Oficial de Médicos de la Provincia de Cádiz, 224-226.

- Herrera Rodríguez, F. (2007). La obra sanitaria de Leonardo Rodrigo Lavín (1867-1950). Cádiz: Fundación Provincial de Cultura (Diputación de Cádiz).

- Herrera Rodríguez, F. (2011). Un viaje a Newark en busca de la polio. Cultura de los Cuidados, 31, 30-40.

- Laval R., E. (2007). Anotaciones para la historia de la poliomielitis en Chile. Revista chilena de infectología,
3: $247-250$.

- Marchena Domínguez, J. (1997). Cádiz, 1947: El año de la explosión. Cádiz: Ayuntamiento de Cádiz.

- Nájera, R. (2006). Florencio Pérez Gallardo (1917-2006). Rev. Esp. Salud Pública, 80: 605-608.

- Paul, John R. (1956). Epidemiología de la poliomielitis. Boletín de la Oficina Sanitaria Panamericana. Disponible en http://hist.library.paho.org/Spanish/BOL/ v40n6p521.pdf (Consultado el 2 de diciembre de 2014).

- Porras Gallo, M.I., Ayarzagüena Sanz, M., Heras Sarlord de las, J. y Báguena Cervellera, Ma.J. (coords.) (2013). El drama de la polio. Un problema social y familia en la España franquista. Madrid: Los Libros de la Catarata.

- Rodríguez Sabalette, P. (1926). De la actividad tónica de los músculos estriados y su posible registro gráfico. Cádiz: Tip. M. Cerón. 